\title{
IMMUNOHISTOCHEMICAL DETECTION OF KERATIN, ACTIN AND TYPE IV COLLAGEN IN SERIAL SECTIONS OF METHACARN-FIXED BREAST CANCER TISSUES
}

\author{
Hrdeto SENZAKI, Airo TSUbURA, Tetsuji SHOJI, Hiyoshi OKADA, \\ HIDEKI TAKAHASHI AND SOTOKIGHI MORII \\ Department of Pathology, Kansai Medical University, Moriguchi, Osaka 570
}

Received for publication September 30, 1991 and in revised form October 29, 1991

\begin{abstract}
Correlations among the immunolocalizations of keratin, actin and type IV collagen were investigated in serial sections of methacarn-fixed, paraffin-embedded mastectomy specimens taken from infiltrating breast cancer patients. Stainings of the filaments in pretreated sections with actinase were often weaker and/or less apparent in cancer cells than in normal mammary gland cells. If at least $30 \%$ of living cancer cells were stained, the case was scored positive. Positivity for 312C8-1 specific for basal cell type keratin 14 was observed in 8 of 60 cases, while for NCL-5D3 specific for luminal cell type keratins, positivity was observed in 57 of 60 cases. Five cases positive for HHF35 specific for muscle actin were also positive for 312C8-1 and NCL-5D3. Type IV collagen in cancer foci was patchy and/or absent, but small cancer nests surrounded completely by continuous type IV collagen, termed "in situ carcinoma components" ${ }^{\text {" were found }}$ in 25 of 60 cases. In all the components, stainings with 312C8-1 and/or NCL5D3 were found in some cancer cells, and the former was almost always seen in a basal orientation within the components. In conclusion, keratin 14-positive basal cells could be identified in paraffin sections, and these findings suggest that the basal cells are closely related to continuous type IV collagen and a progressive loss of the cells may promote metastasis through fragmented type IV collagen.
\end{abstract}

The most malignant aspect of neoplasia is metastasis, a process involving a complex series of steps. The remarkable correlation between metastasis and secretion of type IV collagenolytic protease suggests that basement membrane protein, type IV collagen, may play a specific role in the metastatic process (4). The occurrence of basement membrane in neoplastic breast lesions has been extensively studied using antibodies to type IV collagen, with the basement membrane always surrounding ducts and lobules in normal breast tissue, benign breast lesions and in situ malignancies of the breast, but very often being patchy within invasive breast cancers $(13,16,18)$. Conflicting views exist in the literature with respect to the presense or absence of basement membrane components within infiltrating breast cancers, and type IV collagen, a basement membrane component, was reported not to be detected in the absence of keratin

Address for reprints requests: Sotokichi Morii, M.D. Department of Pathology, Kansai Medical University, Fumizono 1, Moriguchi, Osaka 570, Japan. 14-positive basal cells within invasive breast carcinomas (16). Basal (myoepithelial-like) cells are thought to be involved in basement membrane production (15). It should be pointed out that in our experience, almost all breast cancer patients die of metastatic complications, and that a few metastases have been noted in spontaneously occurring and chemically induced mammary cancers of rodents. The authors reported that the immunolocalization of basal cell keratin 14 was more often seen in rodent mammary cancers than in human breast cancers (11, 12). Moreover, loss of keratin 14-positive cells in transplantable sublines of mouse mammary carcinoma has been recently reported by the authors to be accompanied by the acquisition of lung-colonizing capability and patchy type IV collagen surrounding cancer nests (10). Keratin 14 has been thought to be identified only in cryostat sections $(3,11,17)$, but it can now be seen in methacarn-fixed, dewaxed and actinasepretreated sections. In this paper, correlations among the immunolocalizations of some cytokeratins, muscle actin and type IV collagen are investigated in serial sec- 
tions of human breast cancer tissues.

\section{MATERIALS AND METHODS}

Mastectomy tissue specimens were obtained from 60 patients treated in 1989-91 at Kansai Medical University Hospital, who suffered from infiltrating breast cancers ( 31 solid tubular, 8 papillotubular, 20 scirrhous and 1 lobular carcinomas). In the sections, a small cancer nest surrounded completely by continuous type IV collagen, tentatively termed an "in situ carcinoma component", was seen in 25 cases (11 solid tubular, 4 papillotubular, 9 scirrhous and 1 lobular carcinomas). Normal breast tissues were observed in uninvolved areas of the breasts removed with the cancer at mastectomy in 4 cases.

Tissue specimens, $3-4 \mathrm{~mm}$ in thickness, were fixed in methacarn ( 6 volumes of methanol +3 volumes of chloroform +1 volume of glacial acetic acid) as soon as possible after surgery. After fixation for 6-12 hr, they were immersed successively in absolute ethanols for 4-6 hr and chloroform for $3 \mathrm{hr}$, embedded in paraffin and cut into serial $4 \mu \mathrm{m}$ sections for immunohistochemical studies. Sections sequential to those used for immunostainings were examined routinely to confirm the histopathological findings. The dewaxed sections for immunoperoxidase stainings were pretreated with $0.01 \%$ actinase (Kaken Pharmacol. Co., Tokyo) in $0.01 \mathrm{M}$ phosphate buffered saline, $\mathrm{pH} 7.2$, at $37^{\circ} \mathrm{C}$ for $15 \mathrm{~min}$, rinsed in $0.01 \mathrm{M}$ Tris-HCl buffer, $\mathrm{pH} \mathrm{7.2,} \mathrm{and} \mathrm{then} \mathrm{treated} \mathrm{with} \mathrm{the}$ primary antibody or antiserum for $1 \mathrm{hr}$. The monoclonal antibodies and rabbit antiserum used in this study and their sources and dilutions are listed in Table $1(1,3,7,14)$. The diluent was Tris- $\mathrm{HCl}$ buffer, $\mathrm{pH} 7.2$, and all immunostaining steps took place at room temperature. The ABC method using peroxidase-conjugated antibodies was employed for immunohistochemistry (5). Normal goat serum, biotinylated anti-rabbit serum and avidin-biotin complex were purchased as Vectastain ABC kits from Vec- tor Lab., Burlingame, CA. The procedures were performed according to the directions of Vector Lab. Antigenic sites were visualized using a freshly prepared solution of diaminobenzidine (Wako Pure Chem., Osaka) in $0.01 \%$ hydrogen peroxide in the usual way. Sections were counterstained faintly with Gill's hematoxylin, cleared and mounted in balsam. Controls for immunostainings involved substitution of the antibody or antiserum with Tris-HCl buffer or normal rabbit serum.

The cases were scored positive when at least $30 \%$ of the living cancer cells were labelled diffusely throughout the sections with the antibody. In general, negative sections consisted entirely of unlabelled cancer cells. Immunostainings in remnants of normal mammary glands situating within and/or around the cancer foci were excluded for these evaluations. On the other hand, all labelling pictures were noted in the "in situ carcinoma component", and the case was scored positive if the labelling was observed in some components. Cytoplasmic stainings of the filaments were classified as either densely brownish black (\#), brownish black $(H)$, or brown $(+)$. Staining pictures of type IV collagen were classified as continuous, patchy, or absent (-).

\section{RESULTS}

Monoclonal antibody NCL-5D3 labelled predominantly luminal gland cells of the mammary ducts and lobules, and their cytoplasmic stainings were ( $\mathrm{H})$ in almost all normal mammary glands. On the contrary, monoclonal antibody 312C8-1 labelled only the epithelial cells situated between the luminal gland cells and the basement membrane. Their cytoplasmic stainings classified as (WH) were seen in all the positive basal cells, most of which were labelled also with monoclonal antibody HHF35. The characteristic basal (myoepithelial-like) cells were located continuously in the outer layer of mammary ducts, but were scattered in the outer portions of mam-

TABLE 1. Specificities, Sources and Dilutions of Antibodies and Antiserum Used

\begin{tabular}{llll}
\hline Antibody and antiserum & \multicolumn{1}{c}{ Specificity } & \multicolumn{1}{c}{ Source } & Dilution \\
\hline NCL-5D3 & Keratins 8, 18, 19 & Becton Dickinson & $1: 800$ \\
312 C8-1 & Keratin 14 & Supplied by Dr. Dairkee & $1: 500$ \\
$\begin{array}{l}\text { HHF35 } \\
\begin{array}{l}\text { Anti-type IV collagen } \\
\text { rabbit antiserum }\end{array}\end{array}$ & Muscle actin & Biogenex & $1: 300$ \\
\hline
\end{tabular}


mary lobules. In normal breasts, type IV collagen appeared as a relatively thick layer in the basement membrane surrounding mammary ducts and lobules, and the staining pattern was continuous in all the examined cases.

Cytoplasmic staining pictures of keratin 14 were detected in positive cases $(13 \%)$ : solid tubular $(3 / 31$, $10 \%)$; papillotubular $(3 / 8,38 \%)$; scirrhous $(2 / 20$, $10 \%)$; and lobular $(0 / 1,0 \%)$. Their staining patterns were varied. Some were basally oriented (Fig. 1), and others were diffuse or scattered (Fig. 2). A few cancer cells labelled with 312C8-1 showing $(+)$ or $(+)$ staining were found in some cancer foci in 6 negative cases for 312C8-1, with the other 45 negative cases revealing entirely negative sections for 312C8-1 (Fig. 3). Five positive cases for 312C8-1 showing (H) staining were also labelled with HHF35, though all the other cases were HHF35-negative. Three other positive cases for 312C8-1 showing $(+)$ or $(H)$ staining (Fig. 4) were also labelled strongly with NCL-5D3 (Fig. 6), but not with HHF35 (Fig. 5). On the other hand, cytoplasmic staining pictures with NCL-5D3 were seen clearly in almost all cancer cells of the positive cases (Figs. 5, 7, 8). However, 3 cases of solid tubular carcinoma revealed entirely negative sections with NCL-5D3. The positivity with NCL-5D3 was counted in 57 of 60 cases (95\%), as indicated in Table 2. Relatively weak stainings were seen generally, compared with those in normal mammary glands. In particular, the stainings were predominantly weak in most scirrhous carcinomas (Fig. 8). Type IV collagen was observed fragmented, patchy and/or absent in these cancer tissues.

Some small cancer nests were seen to be surrounded completely by a continuous type IV collagen. Such tentatively termed "in situ carcinoma components" could be found in the sections of 25 cases out of 60 infiltrating breast cancer cases, as indicated in Table 2. In all the "components", the cells labelled with NCL5D3 or 312C8-1 were identified distinctly. These cells labelled with 312C8-1 were always seen in a basal orientation within the "components". For example, in serial sections, such basally oriented keratin 14positive cells were observed in 2 cancer nests surrounded completely by continuous type IV collagen, i.e. the "components", but no positive cells with 312C8-1 were detected in another cancer nests having no continuous type IV collagen (Figs. 9, 10). On the other hand, many positive cells with $312 \mathrm{C} 8-1$ were seen scatteringly in the central portion of the cancer nest not surrounded by continuous type IV collagen (Figs. 11, 12). In brief, the existence of continuous type IV col-

TABLE 2. Positivities of Immunostainings of Keratins, Actin and Type IV Collagen in Mastectomy Specimens from 60 Infiltrating Breast Carcinoma Patients

\begin{tabular}{|c|c|c|c|c|c|c|c|c|c|c|c|c|c|c|c|}
\hline \multirow{5}{*}{$\begin{array}{l}\text { Antibodies } \\
\text { Samples } \\
\begin{array}{l}\text { Normal breast tissue } \\
\text { basal cells } \\
\text { luminal cells }\end{array}\end{array}$} & \multirow{5}{*}{ Numbers } & \multicolumn{4}{|c|}{$\begin{array}{c}\text { NCL-5D3 } \\
(\mathrm{K} 8,18,19) \\
\end{array}$} & \multicolumn{4}{|c|}{$\begin{array}{c}312 \mathrm{C} 8-1 \\
(\mathrm{~K} 14)\end{array}$} & \multicolumn{4}{|c|}{$\underset{\text { (actin) }}{\text { HHF35 }}$} & \multirow{2}{*}{\multicolumn{2}{|c|}{$\begin{array}{c}\text { Anti-type IV } \\
\text { collagen serum } \\
\begin{array}{c}\text { continuous } \\
\text { patchy or - }\end{array}\end{array}$}} \\
\hline & & \multirow{4}{*}{$\begin{array}{l}\text { H } \\
0 \\
4\end{array}$} & \multirow{4}{*}{$\begin{array}{l}H \\
\\
0 \\
0\end{array}$} & \multirow{4}{*}{$\begin{array}{c}+ \\
0 \\
0\end{array}$} & \multirow{4}{*}{$\begin{array}{l}- \\
\\
4 \\
0\end{array}$} & \multirow{4}{*}{$\begin{array}{l}\text { H } \\
\\
4 \\
0\end{array}$} & \multirow{4}{*}{$\begin{array}{l}H \\
0 \\
0\end{array}$} & \multirow{4}{*}{$\begin{array}{r}+ \\
0 \\
0\end{array}$} & \multirow{4}{*}{$\begin{array}{c}- \\
\\
0 \\
4\end{array}$} & \multirow{4}{*}{$\begin{array}{l}\text { H } \\
0 \\
0\end{array}$} & \multirow{4}{*}{$\begin{array}{l}H \\
4 \\
0\end{array}$} & \multirow{4}{*}{$\begin{array}{l}+ \\
+ \\
0 \\
0\end{array}$} & \multirow{3}{*}{$\begin{array}{c}- \\
0 \\
0\end{array}$} & & \\
\hline & & & & & & & & & & & & & & 4 & 0 \\
\hline & & & & & & & & & & & & & & & \\
\hline & & & & & & & & & & & & & 4 & & \\
\hline $\begin{array}{l}\text { Infitrating breast } \\
\text { carcinona }\end{array}$ & 60 & 0 & 27 & 30 & 3 & 0 & 5 & 3 & 52 & 0 & 0 & 5 & 55 & 0 & 60 \\
\hline Solid tubular & 31 & 0 & 18 & 10 & 3 & 0 & 3 & 0 & 28 & 0 & 0 & 3 & 28 & 0 & 31 \\
\hline Papillotubular & 8 & 0 & 6 & 2 & 0 & 0 & 2 & 1 & 5 & 0 & 0 & 2 & 6 & 0 & 8 \\
\hline Scirrhous & 20 & 0 & 2 & 18 & 0 & 0 & 0 & 2 & 18 & 0 & 0 & 0 & 20 & 0 & 20 \\
\hline Lobular & 1 & 0 & 1 & 0 & 0 & 0 & 0 & 0 & 1 & 0 & 0 & 0 & 1 & 0 & 1 \\
\hline $\begin{array}{l}\text { In situ carcinoma } \\
\text { components within }\end{array}$ & 25 & 0 & 15 & 10 & 0 & 0 & 9 & 16 & 0 & 0 & 3 & 5 & 17 & 25 & 0 \\
\hline Solid tubular carc. & 11 & 0 & 11 & 0 & 0 & 0 & 2 & 9 & 0 & 0 & 0 & 2 & 9 & 11 & 0 \\
\hline papillotubular carc. & 4 & 0 & 3 & 1 & 0 & 0 & 3 & 1 & 0 & 0 & 3 & 1 & 0 & 4 & 0 \\
\hline scirrhous carcinoma & 9 & 0 & 0 & 9 & 0 & 0 & 4 & 5 & 0 & 0 & 0 & 2 & 7 & 9 & 0 \\
\hline lobular carcinoma & 1 & 0 & 1 & 0 & 0 & 0 & 0 & 1 & 0 & 0 & 0 & 0 & 1 & 1 & 0 \\
\hline
\end{tabular}

Cytoplasmic stainings of the filament are classified as densely brownish black (Ht), brownish black ( $H$ ), brown $(+)$ and none $(-)$. Staining patterns of type IV collagen are classified into continuous, patchy and absent (-), and the pattern is decided according to more than half of findings in the case. 


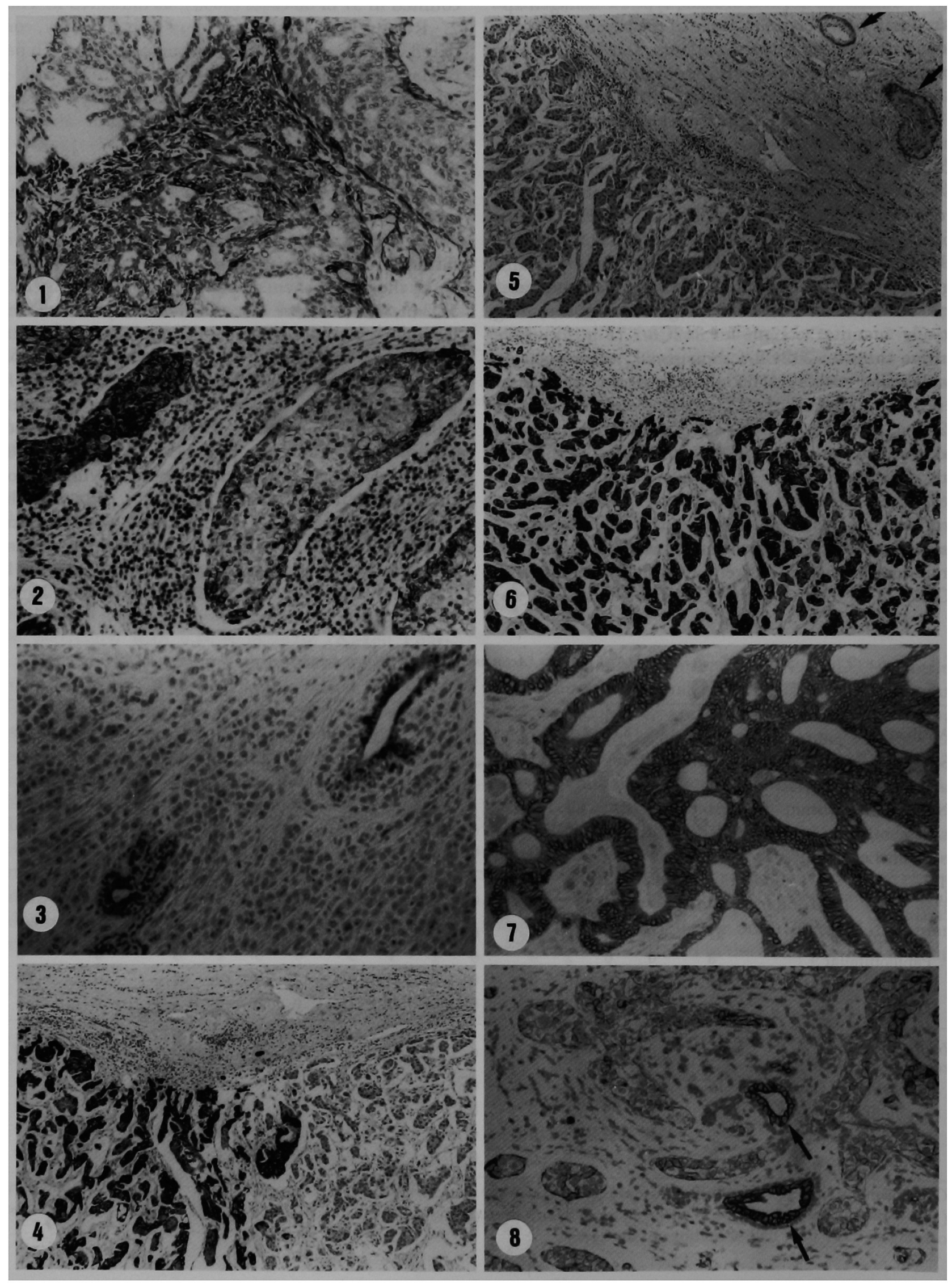




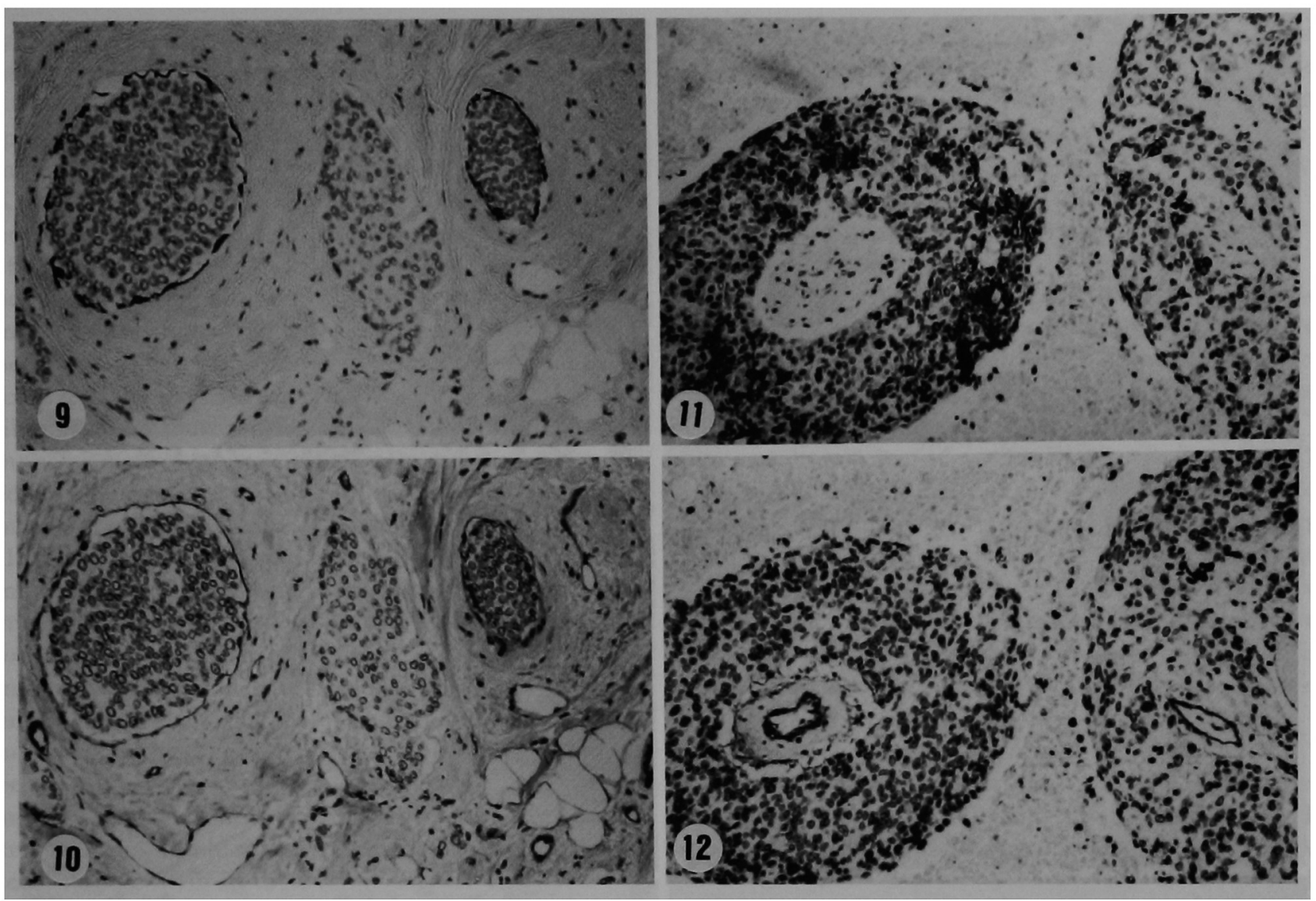

Figs. 9-10. A solid tubular carcinoma. $\times 175$ Labellings with $312 \mathrm{C8}-1$ are seen in basally oriented epithelial cells within some cancer nests (components) but not in other cancer nests (Fig. 9). Continuous type IV collagen is detected in the peripheries of only the cancer nests with keratin 14-positive, basally oriented epithelial cells (components), in addition to the basement membrane of the vessels (Fig. 10).

Figs. 11-12. A solid tubular carcinoma. $\times 175$ Much of labelling with 312C8-1 is seen scattered in some cancer nests (Fig. 11), but type IV collagen is not detected in their peripheries though it can be seen in the basement membrane of the vessels (Fig. 12).

lagen in the periphery of cancer nests was closely correlated with basally oriented keratin 14-positive basal cells. The epithelial cells labelled with HHF35 were identified distinctly in some "components" of 6 cases, showing similar staining pattern to the keratin 14positive cells. In the "components" of 19 other cases, the basally oriented epithelial cells were labelled with 312C8-1 but not with HHF35.

\section{DISCUSSION}

The epithelial lining of the mammary gland con-

Fig. 1. Labelled cancer cells with $312 \mathrm{C8}-1$ in a papillotubular carcinoma. $\times 200$ Many of them are basally oriented in cancer foci.

Fic. 2. Labelled cancer cells with $312 \mathrm{C8}-1$ in a solid tubular carcinoma. $\times 175$ They scatter in some sections of cancer nests.

Fig. 3. Labellings with 312C8-1 in a lobular carcinoma. $\times 175$ Some basal cells are labelled in remnants of normal mammary glands, but the cancer cells are entirely negative.

Figs. 4-6. A solid tubular carcinoma. $\times 175$ Labellings with $312 \mathrm{C} 8-1$ are seen in half of the cancer cells in the cancer focus (Fig. 4), and strong stainings with NCL-5D3 are seen in almost all cancer cells in the same cancer focus (Fig. 6). The labelling with HHF35 is not seen in the same cancer focus though smooth muscles of the vessels (arrows) are labelled with HHF35 (Fig. 5 ).

Fig. 7. Labelled cancer cells with NCL-5D3 in a papillotubular carcinoma. $\times 175$ Moderate (H) stainings are seen in almost all cancer cells.

FIG. 8. Labelled cancer cells with NCL-5D3 in a scirrhous carcinoma. $\times 175$ Slight $(+)$ stainings are seen in almost all cancer cells, although strong $(\mathrm{H})$ stainings are seen in all luminal cells of remnants of normal mammary gland (arrows). 


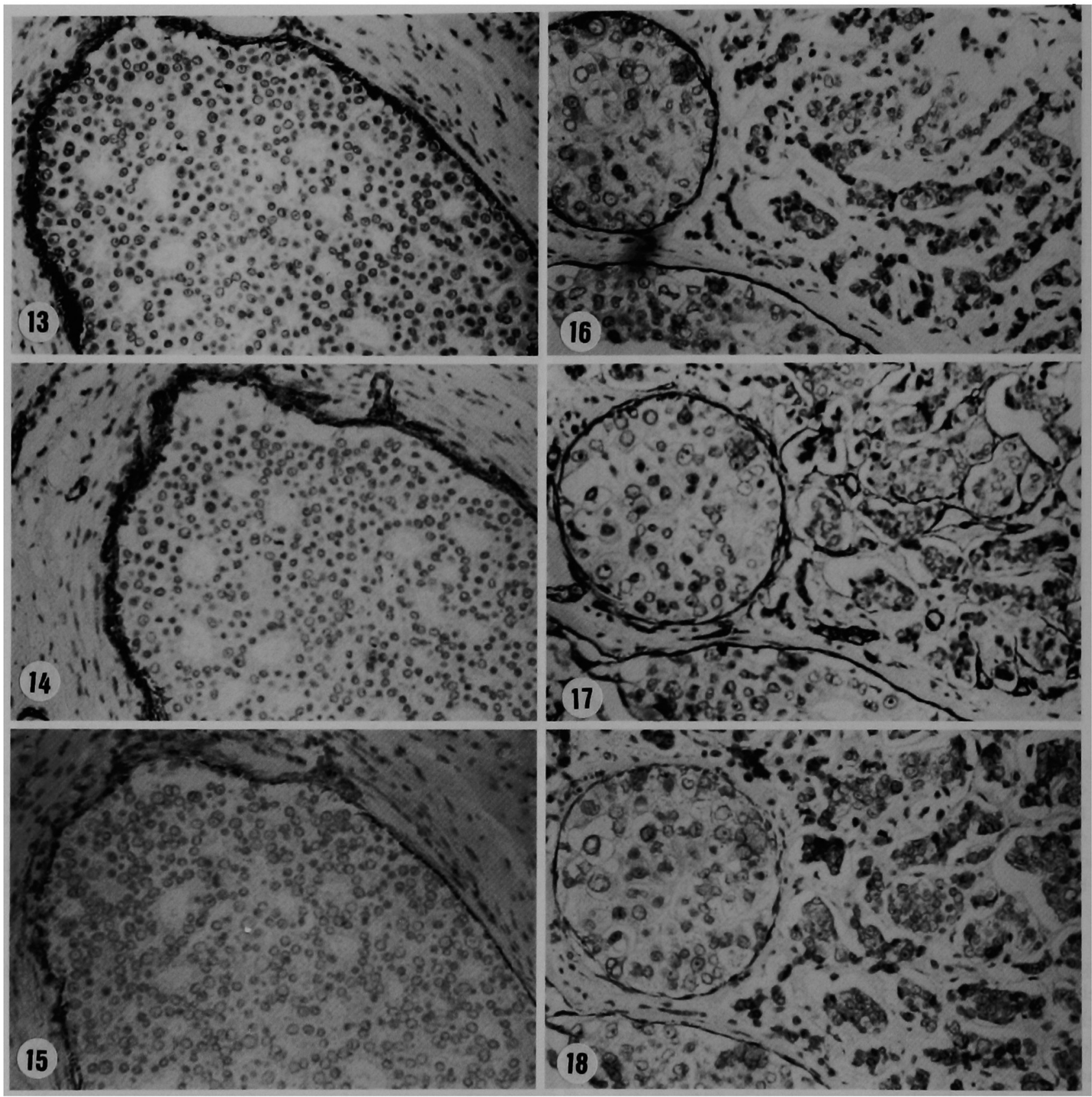

FIGs. 13-15. An “in situ carcinoma component” of a solid tubular carcinoma. $\times 175$ Stainings of keratin 14 (Fig. 13), type IV collagen (Fig. 14) and muscle actin (Fig. 15) can be seen in the periphery of the component.

Figs. 16-18. "In situ carcinoma components" in a scirrhous catcinoma. $\times 350$ Stainings of keratin 14 (Fig. 16), type IV collagen (Fig. 17) and muscle actin (Fig. 18) can be seen in the periphery of the components. Some cancer cells surrounding the "components" are also labelled with 312C8-1 (Fig. 16) and HHF35 (Fig. 18) and entwined by type IV collagen (Fig. 17).

sists of two different types of epithelial cells: bsal (myoepithelial) and luminal. These two cell types contain different keratin subtypes, i.e. basal cells contain at least keratin 5, 14 and 17 , while luminal cells express keratin 7, 8, 18 and 19 (9). Several monoclonal antibodies can differentiate immunohistochemically between basal and luminal cells in the breast tissues. Organic solvent-containing fixatives including methacarn possess excellent properties for the preservation of keratin antigenicities in human breast and rodent mammary tumor tissues $(2,11-13)$. Dairkee et al. first described how an antibody, 312C8-1, specifical- 
ly reacts with myoepithelial (basal) cells in the mammary glands (3). This antibody was produced against a $51 \mathrm{KD}$ keratin isolated from a mammary carcinoma (presumably keratin 14 , calculated at a $50 \mathrm{KD}$ molecular weight). Other monoclonal antibodies, KA-1, LL002, RCK107, RKH4, and LL025, can be used for the identification of basal cells $(6,8,11,12$, $16,17)$ in human breast and rodent mammary tissues, but most of these antibodies have been available only in cryostat sections. In this study, useful advance has been provided by the proper digestion of methacarnfixed sections with actinase before applying the first antibody. The mechanism is not entirely understood, but it seems that some of the protein crosslinking caused by the fixative is released by actinase digestion and more antigenic sites are made available to the antibody (12). These stainings of keratin in digested methacarn-fixed sections were similar to those in cryostat sections. Such digestion was also necessary for the demonstration of type IV collagen (13). Immunolocalizations of keratins labelled with NCL-5D3 and muscle actin labelled with HHF35 were not modified by actinase digestion, but these stainings became a little weaker. Therefore, correlations among the immunolocalizations of basal cell type keratins and luminal cell type keratins in epithelial cells, muscle actin in myoepithelial cells, and type IV collagen in basement membranes could be investigated in serial sections of the infiltrating breast cancer tissues.

The overall patterns of keratin expression were different in normal breasts and breast carcinomas. Stainings in the latter were less apparent and/or weaker, depending on the cellular differentiation. When antibody specific for the intermediate filament labelled at least $30 \%$ of the living cancer cells diffusely throughout the section, the case was scored as antigenpositive. Basal cell type keratin 14-positive-cases were counted only in $13 \%$ of examined cases, while luminal cell type keratin-positive cases were seen in 95\%. Muscle actin-positive-cases were also counted as basal cell type keratin-positive cases, but they were noted only in $8 \%$ of examined cases. Our data agree with other previously reported data observed in cryostat sections $(6,12,16,17)$ and support the hypothesis that human breast carcinoma with basal (especially myoepithelial) cell differentiation is very rare. Moreover, unlike in normal mammary glands showing two different keratin subtypes, stainings with both 312C8-1 and NCL-5D3 were sometimes seen in the cancer cells. Staining of keratins was generally weaker than that in normal mammary gland cells, and 3 cases were completely negative for all the examined filaments. Stainings of both keratin 14 and muscle actin were detected not only continuously in the basal orientation but were also scattered throughout the sections of cancer foci, and luminal cell type keratins were found in peripheral portions of sections of most cancer foci. The above-mentioned abnormal stainings of keratins and muscle actin express a cellular atypia of breast carcinoma cells.

Type IV collagen was detected in a fragmented and/or patchy way in most cancer foci, and it was absent in a few other cancer foci. Some small cancer nests, however, were completely surrounded by continuous type IV collagen. Such tentatively termed "in situ carcinoma components" were observed in 25 cases, $42 \%$ of the examined breast cancer patients. In all the "components", stainings of both basal cell type keratin 14 and luminal cell type keratins were identified, and the former was seen continuously in basal orientation. Stainings of muscle actin were observed in a pattern similar to that of basal cell type keratin, but could not be identified in all the "components". Distinctly continuous staining of muscle actin in periphery of the "component" might lead one to suspect an intraductal progression of breast cancer cells. Moreover, a continuous arrangement of basally oriented keratin 14-positive cells was closely correlated to a continuous deposition of type IV collagen in the periphery of less malignant "components". Progressive loss of basal cells in the cancer foci may promote metastasis through the fragmentation and/or disappearance of continuous type IV collagen. Recently, Wetzels et al. using monoclonal antibodies LL025 (specific for keratin 17) and LH7.2 (specific for type VII collagen) suggested that immunostainings with both of these antibodies were more useful in this field than those of keratin 14 and type IV collagen (10, 11). Their observations were carried out on cryostat sections. Further investigations are necessary.

\section{REFERENCES}

1. Augus, B., Purvis, J., Stock, D., Westley, B. R., Samson, A. C. R., Routledge, E. G., Carpenter, F. H. and Horne, H. W.: NCL-5D3: A new monoclonal antibody recognizing low molecular weight cytokeratins effective for immunohistochemistry using fixed paraffin-embedding tissue. J. Pathol. 153; 377-384, 1987.

2. Battifora, H. and Kopinski, M.: The influence of protease digestion and duration of fixation on the immunostaining of keratins. A comparison of formalin and ethanol fixation. J. Histochem. Cytochem. 34; 1095-1100, 1986.

3. Dairkee, S. H., Blaynay, C., Smith, H. S. and Hackett, 
A. J.: Monoclonal antibody that defines human myoepithelium. Proc. Natl. Acad. Sci. USA 82; 7409$7413,1985$.

4. Garbisa, S., Pozzatti, R., Muschel, R. J., Saffiotti, J., Ballin, M., Goldfarb, R. H., Khoury, G. and Liotta, L. H.: Secretion of type IV collagenolytic protease and metastatic phenotypes: Induction by transfection with cHa-ras but not with c-Ha-ras plus Ad2-Ela. Cancer Res. 47; 1523-1528, 1986.

5. Hsu, S. M., Raine, L. and Fanger, H.: Use of avidinbiotin-peroxidase complex $(\mathrm{ABC})$ in immunoperoxidase technique. A comparison between $\mathrm{ABC}$ and unlabelled antibody (PAP) procedures. J. Histochem. Cytochem. 29; 577-580, 1981.

6. Nagle, R. B., Boecker, W., Davis, J. R., Heid, H. W., Kaufmann, M., Lucas, D. O. and Jarasch, E-D.: Characterization of breast carcinomas by two monoclonal antibodies distinguishing myoepithelial from luminal epithelial cells. J. Histochem. Cytochem. 34; 869-881, 1986.

7. Oikawa, T., Iwaguchi, T., Kimura, M. and Matsuzawa, A.: Purification and characterization of type IV collagen from mouse kidney. Chem. Pharm. Bull (Tokyo) 34; 789797, 1986.

8. Purkis, P. E., Steel, J. B., Mackenzie, I. C., Nathrath, W. B. J., Leigh, I. M. and Lane, E. B.: Antibody markers of basal cells in complex epithelia. J. Cell Sci. 97; 39-50, 1990.

9. Taylor-Papadimitriou, J. and Lane, E. B.: Keratin expression in the mammary gland. In "The Mammary Gland: Development, Regulation and Function", ed. by M. C. Neville and C. W. Daniel, Plenum Press, New York and London, 1987, pp 181-215.

10. Tsubura, A., Inui, T., Morii, S., Dairkee, S. H., Oikawa, T. and Matsuzawa, A.: Loss of basal cell phenotypes with acquisition of lung-colonizing capability in mouse mammary tumors. Breast Cancer Res. Treat. 17; 239-243, 1990

11. Tsubura, A., Inui, T., Senzaki, H., Hatano, T., Morii,
S. and Dairkee, S. H.: Immunolocalization of the human basal epithelial marker monoclonal antibody 312C8-1 in normal tissue and mammary tumors of rodents. Virchows Archiv [A] 415; 533-538, 1989.

12. Tsubura, A., Okada, H., Senzaki, H., Hatano, T. and Morii, S.: Keratin expression in the mormal breast and in breast carcinoma. Histopathology 18; 517-622, 1991.

13. Tsubura, A., Shikata, N., Inui, T., Morii, S., Hatano, T., Oikawa, T. and Matsuzawa, A.: Immunohistochemical localization of myoepithelial cells and basement membrane in normal, benign and malignant human breast lesions. Virchows Archiv [A] 413; 133-139, 1988.

14. Tsukada, T., Tippens, D., Gorden, D., Ross, R. and Gown, A. M.: HHF35. muscle actin specific monoclonal antibody I. Immunohistochemical and biochemical characterization. Am. J. Pathol. 126; 51-66, 1987.

15. Warburton, M.J., Mitchell, D., Omerod, E. J. and Rudland, P.: Differentiation of myoepithelial cells and basement membrane proteins in the resting, pregnant, lactating, and involuting rat mammary gland. J. Histochem. Cytochem. 30; 667-676, 1982.

16. Wetzels, R. H.W., Holland, R., van Haelst, U. J. G. M., Lane, E. B., Leigh, I. M. and Ramaekers, F. C. S.: Detection of basement membrane components and basal cell keratin 14 in non-invasive and invasive carcinomas of the breast. Am. J. Pathol. 134; 571-579, 1989.

17. Wetzels, R. H.W., Kuijpers, H. J. H., Lane, E. B., Leigh, I. M., Troyanovsky, S. M., Holland, R., van Haelst, U. J. G. H. and Ramaekers, F. C. S.: Basal cellspecific and hyperproliferation-related keratins in human breast cancer. Am. J. Pathol. 138; 751-763, 1991.

18. Willebrand, D., Bosman, F. T. and de Goeij, A. F. P. M.: Patterns of basement membrane deposition in benign and malignant breast tumours. Histopathology 10; 1231-1241, 1986. 